\title{
WILHELM DILTHEY EM NOVAS TRADUÇÕES
}

Filosofia e educação: textos selecionados.

Dilthey, Wilhelm. Org. e intr. de Maria Z. C. P. Amaral.

São Paulo: Edusp, 2010. 527 pp.

A construção do mundo histórico nas ciências humanas.

Dilthey, Wilhelm. São Paulo: Ed. Unesp, 2010. 345 pp.

Em 2011 contamos cem anos desde a morte de Wilhelm Dilthey (1833-1911). Por uma coincidência de datas e esforços, duas editoras universitárias de São Paulo publicaram, simultaneamente, dois livros seus, oferecendo uma contribuição importante para adensar o conjunto dos escritos do filósofo disponíveis em língua portuguesa. ${ }^{1}$ Embora não se possa dizer que Dilthey seja um autor desconhecido, os dois volumes circunscrevem o núcleo forte de seus esforços e firmam-se, por essa razão, como referências decisivas para todos os que se interessem pelo autor e pelos problemas por ele tratados. Entretanto, os livros se superpõem em grande parte; a coletânea da Edusp é bem mais extensa do que o livro da Unesp e inclui a parte central deste último, além de muito mais. Em razão disto, esta resenha concentrar-se-á no primeiro deles, deixando claro, desde o início, que muitos dos problemas discutidos encontram lugar também no outro volume.

À diferença de uma certa tradição filosófica que afirmava ser a realidade do mundo exterior uma mera representação, Dilthey afirma deci- didamente que ela é "vida". Este é o cerne de uma outra e nova revolução copernicana, que pretendia resolver os impasses e aporias que afligiam o conhecimento histórico. Em um vazio deixado por Kant, Dilthey, já desde a década de 1860, pretendia oferecer as bases para uma crítica da razão histórica; todo o seu labor gravitou, durante uma longa vida de reflexão, em torno de um nexo de problemas que se referia primordialmente a essa questão. A célebre Introdução às ciências do espírito, de 1883, ocupa o ponto arquimediano na reflexão do filósofo, ao reconhecer a "autonomia das ciências do espírito" e almejar sua "fundamentação epistemológica”, possibilitando assim a validade dos "conhecimentos da sociedade e da história" (Dilthey, 2010a: 36-37).

O leitor brasileiro pode conferir tudo isso e muito mais, com precisão e variedade, na ótima antologia intitulada Filosofia e educação. O título, contudo, é totalmente equivocado, pois apenas um dos dezessete textos coligidos trata de educação (especificamente: pedagogia), embora forme sistema com o conjunto. Mas o leitor, 
pelo título, fica sem saber que há textos sobre hermenêutica, estética, epistemologia e teoria do conhecimento, ética e psicologia. A seleção é variada e rica; a leitura exige atenção e cuidado, pois trata-se de um filósofo informado, cuidadoso e de reflexão sofisticada.

O ponto de partida de sua problematização pode ser encontrado, como foi dito, na busca da fundamentação do conhecimento no âmbito das "ciências do espírito", uma expressão que recobre o que hoje entendemos por "humanidades". Mas que elas sejam assim denominadas faz toda a diferença: não haveria outro termo que pudesse concentrar a força e o específico da reflexão feita na Alemanha, ao mesmo tempo que mobiliza toda uma semântica destilada e processada no arco que vai do último quartel do século XVIII até a Grande Guerra, e cujas ressonâncias atuam ainda hoje. ${ }^{2}$ Elevar a validade do conhecimento das ciências do espírito ao grau de legitimidade já então alcançado pelas ciências da natureza era fundamental, no momento - transcorrido o século XIX - em que aquelas haviam se institucionalizado, com a implantação do modelo humboldtiano nas universidades.

Pode parecer estranho, ou ao menos inusitado, que uma preocupação de natureza epistemológica com relação às ciências do espírito desague em uma filosofia que privilegie o conceito de "vida" - e que acabe sendo rotulada como "filosofia da vida". Não obstante, isto tem sua razão de ser: o mundo histórico, diz Dilthey, é "a manifestação da própria vida em sua diversidade e profundeza" (Dilthey, 2010a: 40).
Destarte, a compreensão do mundo histórico, do fazer e agir humanos, dirige-se, em última instância, para a vida; somente compreendendo-a teremos a chave-mestra para a compreensão do mundo social e histórico, ou seja, do mundo no qual vivem os seres humanos.

Isto exige um desvio pela psicologia. É no âmbito de uma psicologia cognitiva, das condições da consciência, que Dilthey procura estabilizar os fundamentos da compreensão histórica. Conhecimento depende de consciência; consciência depende de ato psíquico, e este, por sua vez, remete a uma base vital. Aqui surge a noção de "vivência" - que não deve, em absoluto, ser apressadamente contraposta à experiência, como uma certa (des) fortuna crítica costumou fazer - como capacidade de percepção do mundo histórico. Em suas próprias palavras (uma amostra, para que o leitor procure mais): "se alguém desejasse apagar seu próprio eu, para ver as coisas como são, deixaria de existir, com essa extinção, o próprio impulso de querer ver. Porque é o acréscimo da vivência que em toda apercepção do histórico transborda do próprio eu para o mundo dos objetos que faz o mundo ser digno de ser visto. Só nesse sentimento de si, nesse ser-para-si, surge a coloração peculiar da representação: surge o meu, o nosso - o que chamamos de vida" (Dilthey, 2010a: 83).

Esse nexo é complexo e Dilthey articula-o histórica e sistematicamente: acompanhando a discussão no âmbito da história da filosofia e buscando oferecer-lhe uma construção lógica - uma 
epistemologia propriamente dita. Tudo isso tem como alvo a delimitação das ciências do espírito, ou seja, o conhecimento fundamentado e legitimado da "realidade histórica, social e humana". Aqui está a base da diferenciação de explicar e compreender, que fez fortuna e para a qual os desenvolvimentos de Dilthey foram decisivos (voltarei ao ponto).

Pois a almejada crítica da razão histórica forja sua própria modalidade de conhecimento: uma hermenêutica que busca compreender aquela realidade histórica, social e humana, mas não propriamente explicá-la, como se fosse um fato físico. E somente pode compreendê-la por ser ela precisamente humana: há um substrato comum, um princípio de congenialidade (a antiga linhagem que parte de Terêncio - "Nada do que é humano me é estranho" - passa por Montaigne - "Chaque homme porte la forme entière de l'humaine condition" [cada homem traz em si a forma inteira da condição humana] - e encontra em Vico sua fundamentação moderna e, com relação a Dilthey, antecessor imediato). ${ }^{3}$

A compreensão do mundo histórico exige a remissão a uma estrutura e regularidade, que se dispõe em vários níveis. Um deles é a situação concreta, histórica, na qual o produto do espírito está incrustado; é daí que nasce a ideia da unidade da época, da época como totalidade histórica, de importância decisiva para a Geistesgeschichte, que frutificou sob a égide dos escritos de Dilthey (mas não só). ${ }^{4}$ Outro, o mais basilar, é a condição humana, o humano que se apresenta, como regularida- de e estrutura, em toda a existência do ser humano, filo e ontogeneticamente falando (Dilthey menciona recorrentemente a "natureza humana").

Ao procurar caracterizar a especificidade das ciências do espírito, Dilthey assinalou que elas dependem de um nexo de vida, expressão e compreensão. Algo da vida é externalizado, levado à expressão e então compreendido. Quando essas três dimensões se concretizam, estamos nos domínios das ciências do espírito.

Também com relação ao desenvolvimento das ciências do espírito - assim como, em particular, com a hermenêutica -, Dilthey opera histórica e sistematicamente. Suas reconstruções históricas acompanham os enfoques sistemáticos, pois ele já havia reconhecido que um não pode prescindir do outro. Esse andamento duplo é, sem dúvida, um dos pontos fortes de sua empreitada, mesmo quando, aos olhos de hoje, suas reconstruções possam nos parecer simples demais. ${ }^{5}$

No plano histórico, Dilthey aponta um processo de desenvolvimento no qual a consciência histórica se eleva, até o seu pleno reconhecimento, no século XIX. É então que o mundo do espírito é decididamente compreendido como histórico, como resultante de um processo de desenvolvimento. Com isso, reconhece-se a importância da própria categoria de desenvolvimento, que será a partir de então uma chave privilegiada para o enfoque histórico, ou seja, para a confrontação com os produtos do espírito. ${ }^{6}$ Em sintonia com a elevação da categoria de desenvolvimento está o método comparativo, o 
procedimento privilegiado da pesquisa dos processos de desenvolvimento, no âmbito das diversas ciências do espírito particulares (a jurisprudência, a teologia, a história, a psicologia, a sociologia, a etnologia, a musicologia, a teoria política, as várias filologias, a pedagogia etc.). ${ }^{7}$

No plano sistemático, a crítica da razão histórica - que pressupõe, portanto, a existência de uma tal razão, mas a enraíza na história - parte da vida e da compreensão. O exterior, que o conhecimento histórico almeja conhecer, é uma exteriorização do interior, que é vida. Do modo mais sintético, Dilthey assim formulou esse problema, que se tornou clássico: "Nas ciências do espírito, o espírito objetivou-se, nelas formaram-se fins e valores realizaram-se, e é precisamente esse elemento espiritual, que tomou forma nelas, que é apreendido pela compreensão" (Dilthey, 2010a: 174-175). O vivenciar dos estados próprios de cada um é a porta que se abre para a compreensão do mundo exterior, espírito objetivado (imagine-se quando, ou se, um abismo se abre entre o vivenciar e o compreender: chegamos a uma disjunção de interior e exterior, que contemporâneos de Dilthey imediatamente compreenderam consumar uma tragédia do espírito, da alma e da cultura). À diferença das ciências da natureza, nas quais conceitos abstratos são articulados aos fenômenos, nas ciências do espírito os nexos são vivenciados, pois remetem à vida, como seu substrato comum. Portanto, no final das contas, o problema das ciências do espírito é o de uma re-tradução: retraduzir-reconduzir o espírito objetivado, a "realidade social-histórico-humana”, à vida, da qual se originou.

Ademais, o esforço de Dilthey não conduz simplesmente um andamento duplo, histórico e sistemático, mas, mais que isso, entrelaça-os como uma espécie de síntese: sua posição busca conjugar, e levar adiante, os problemas formulados tanto pela filosofia crítica como pela escola histórica. Essa é a chave para determinarmos o seu lugar histórico.

Vale destacar que a noção de vida, que não é propriamente biológica, mas em última instância transubjetiva, ${ }^{8} \mathrm{fa}$ culta a ideia dos indivíduos como ponto de cruzamento dos círculos sociais, como já à época de Dilthey a sociologia procurou formular. ${ }^{9} \mathrm{~A}$ isso se liga, ainda, a grande importância atribuída à noção de Wechselwirkung, como possibilidade de saída do beco do causalismo. ${ }^{10}$ A somatória dessas duas ideias resulta na articulação de um espaço comum e compartilhado pelos seres humanos, que vivenciam e compreendem (e assim abrem a possibilidade de se falar em experiência em sentido enfático, à diferença da leitura que força a separação e dicotomiza vivência e experiência). Evidentemente, a linguagem passa a desempenhar nessa arquitetura um papel da maior importância, como dimensão que possibilita e realiza conexões simbólicas. Nesse registro, ela apresenta-se como uma dimensão interssubjetiva, homóloga ao que disse acima acerca da vida. ${ }^{11}$ A importância da linguagem torna o problema da hermenêutica central, na 
medida em que se trata, inicialmente, da compreensão de sentidos legados pela tradição, mormente a palavra escrita, a palavra do passado que nos é transmitida; a seguir há uma extensão da palavra às demais manifestações do espírito.

Por outro lado, Dilthey está atento ao que denomina "formas elementares da compreensão": ela está enraizada na vida prática, e por isso a hermenêutica tem um fundamento já na mais simples das interações humanas. ${ }^{12}$

Seria difícil superestimar a importância atribuída por Dilthey à hermenêutica - e foi por isso que ele se esforçou tanto em formular o seu problema e reconstruir a sua história. Coube a Gadamer definir com clareza o estatuto da hermenêutica em Dilthey: ela é "o medium universal da consciência histórica" (Gadamer, 1965: 228).

E aqui novamente deparamos com uma variação do princípio da congenialidade, dado que "a compreensão é um reecontro do eu no tu. Essa mesmidade do espírito no eu, no tu, em cada sujeito de uma comunidade, em cada sistema da cultura, e, finalmente, na totalidade do espírito e da história universal torna possível a cooperação das diversas realizações nas ciências do espírito" (Dilthey, 2010a: 237, tradução alterada).

Esta é também a base para a articulação de particular e universal no âmbito das ciências do espírito (que dá lugar ao célebre círculo hermenêutico). Em suma, essa relação transcorre sem grandes atribulações, pois há o princípio da congenialidade que, operando pela via da vivência e da com- preensão, ao final tudo une, em uma totalidade apaziguada (Dilthey, 2010a: 196 e 237$).{ }^{13}$

O círculo hermenêutico enlaça parte e todo, explicandum e explicans; a ideia do mundo histórico como um todo, que se articula de modo não-causal pelo conjunto de nexos de efeito que entrelaçam tudo o que é vida e objetivação da vida, é o que possibilita conceber épocas como unidades, algo que frutificou intensamente no âmbito das ciências do espírito particulares até pelo menos a Segunda Guerra mundial. ${ }^{14}$

É do maior interesse buscar compreender como um esforço tão hercúleo e cuidadoso, que se estende por cerca de meio século de reflexão ininterrupta (c. 1860-1911) torna-se, de certo modo, datado. Já no Entreguerras, quando Dilthey era figura obrigatória no debate intelectual, apontou-se o calcanhar de Aquiles de seu esforço: sua confiança inabalável na totalidade.

Creio que podemos entender isso um pouco melhor se remontarmos, por exemplo, a um trabalho como o de Löwith acerca do processo que vai de Hegel a Nietzsche: uma ruptura histórica, que não foi sentida e não surtiu efeitos em Dilthey (Löwith, 1995). Löwith nos mostra como a sociedade burguesa, o trabalho, a cultura, a humanidade e a cristandade são postos em xeque por uma certa filosofia pós-hegeliana; mas nada disso aparece em Dilthey (quando muito, superficialmente). Uma explicação, sem dúvida relevante, é de natureza eminentemente institucional: após 
Hegel, há uma cisão entre filosofia acadêmica e universitária, por um lado, e filosofia, por assim dizer, "crítica", alocada fora da universidade, por outro (quer-se "crítica" face à filosofia oficial, universitária). Dilthey faz parte da linhagem universitária, para a qual todos aqueles filósofos discutidos por Löwith significaram quase nada, ou muito pouco. Em suma, a ruptura que o pensamento "crítico" pós-Hegel procurou reconhecer, formular e ocasionalmente até mesmo impulsionar, não foi percebida pela filosofia universitária, que permaneceu, como demonstrou Köhnke em seu estudo a respeito, no âmbito de problemas deixado em aberto por Kant (donde a predileção, de que Dilthey dá testemunho, pelo problema de uma crítica da razão histórica) (Köhnke, 1986).

O impacto que aparece em Dilthey é "apenas" o da falência da filosofia moderna da consciência, ou seja, de um transcendentalismo, que sua visão histórica repudia em favor da historicidade do mundo e da vida - donde, inclusive, uma certa proximidade sua com a fenomenologia husserliana e, posteriormente, a influência que exerceu no autor de Sein und Zeit (os impactos de Dilthey são muito amplos e variados; suas ondas chegam até nós). Mas uma consciência de crise e ruptura, complexa, multifacetada e radical, tal como indicada no estudo de Löwith - isso não encontramos em Dilthey. ${ }^{15}$

Como quer que seja, a postulação de uma totalidade como aquela que a filosofia de Dilthey reivindica torna-se, ao longo do século XX, cada vez mais problemática e, para muitos, inaceitá- vel. Um outro modo de apontar para esse mesmo problema é afirmar que, embora Dilthey enfatize como poucos a dimensão histórica, ele não percebe, e consequentemente não tematiza, o caráter contraditório do movimento histórico (daí sua confiança inabalável na totalidade e no todo): esse é, creio, um limite do seu pensamento. Novamente, podemos ler em Gadamer a percepção desse problema, formulado por outra via: a compreensão do passado histórico é, em Dilthey, um deciframento (daí a hermenêutica), e não uma experiência histórica (Gadamer, 1965: 228). ${ }^{16}$ O decifrar, pela via da congenialidade, identifica por demais sujeito e objeto, não admitindo não-identidade e contradição.

Havia mencionado o problema da diferenciação de explicar e compreender. Em um dos textos da antologia, o famoso estudo sobre "O nascimento da hermenêutica", Dilthey arrola uma série de aporias envolvidas no processo de conhecimento próprio das ciências do espírito. Uma delas refere-se a uma pretensa polarização entre explicar e compreender, que de fato mais se aplica a alguns contemporâneos seus (como Rickert e Windelband). Com efeito, a teoria do conhecimento buscada por Dilthey é bastante matizada, talvez mesmo pelo fato de o filósofo jamais ter podido levar a cabo os seus planos e muitos de seus escritos maduros restarem inacabados e na forma de fragmentos. Assim, é possível encontrar passagens que sugerem uma separação mais rígida, e outras em que esta é questionada. No mencionado estudo, Dilthey considera 
a distinção impossível no nível prático, pois trata-se de uma questão de grau: é possível falar de explicação no âmbito das ciências do espírito, desde que se trate de aplicar metodicamente no singular os conhecimentos disponíveis, com vistas a um conhecimento pleno. Como quer que seja, pode-se encontrar, na obra de Dilthey, fundamentos para leituras que enfatizem com maior ou menor grau a diferença de explicar e compreender (Dilthey, 2010a: 385; Riedel, 1970: 73; Habermas, 1987: 159, 205).

O processo de compreensão, e a hermenêutica que lhe é correlata, possui um elemento irracional irredutível, que está ligado à uma irracionalidade, também ela irredutível, da vida (Dilthey, 2010a: 263). Essa foi a porta que permitiu toda uma recepção crítica da filosofia diltheyana, que recusava seu irracionalismo e até mesmo antevia nela germes de um irracionalismo político que devastaria a Europa poucos anos após sua morte.

O importante conceito de Wechselwirkung, desenvolvido por Dilthey como uma alternativa às insuficiências insuperáveis do conceito de causa e efeito, é um dos pressupostos da síntese e totalização que mencionei, e também ele remete a um aspecto irracional, dado que se furta à uma fundamentação conceitual plena. Com efeito, forma sistema com a ideia de vida; Dilthey chega a denominá-lo, decerto provocativamente, um "desconceito" (Dilthey, 2010a: 405). Isso tem a ver com o ponto final de seu desenvolvimento, ou um beco sem saída, como preferirão alguns: uma tautologia em torno da noção de vida. "Vivemos simplesmente para viver, atuamos pela própria atividade, nas energias de nosso ser está programado um sistema de propensão, de iniciativas, de atividades, cuja realização é a própria vida" (Dilthey, 2010a: 421). Desta perspectiva, as diversas teleologias tradicionais e pós-tradicionais estão descartadas, mas coloca-se uma tautologia em seu lugar.

Lembremos, entretanto, de que estamos falando de uma vida de teor transubjetivo (o termo é meu, na falta de melhor); por conseguinte, a referência não é a vida do indivíduo, mas a história, como processo no qual essa dimensão transubjetiva se desdobra.

Dilthey foi profundamente afetado pela percepção da historicidade do tempo histórico no século XIX. ${ }^{17}$ História e sociedade são, para ele, termos-chave: não aceita nem o indivíduo isolado, nem uma lei abstrata de desenvolvimento. Os nexos concretizam-se nos grupos sociais - da família e da horda ao Estado moderno - e nos processos variados, imprevisíveis e únicos do transcurso histórico. Procurar leis abstratas de desenvolvimento - como, por exemplo, nos domínios da pedagogia - é o maior equívoco em que podem incorrer as ciências do espírito. Nem mesmo a filosofia pode se dar ao luxo de uma metafísica, no final das contas impossível (Dilthey, 2010a: 453); somente o labor constante e infindo de uma consciência histórica permite aferir assintoticamente a realidade do mundo e da vida. Dilthey defende uma teoria das concepções de mundo que permitiria, mediante um tratamento 
histórico, descrever como, ao longo de tempo e espaço, diferentes concepções de mundo se apresentam, e aferir sua verdade histórica; essa teoria seria, na mesma medida, uma resposta às críticas de relativismo. Aqui reaparece o mencionado método comparativo. No âmbito dessa arquitetura, cabe à filosofia - seguindo a linhagem de Hegel e Humboldt - a tarefa de fundamentar e integrar o conjunto das ciências do espírito; a filosofia deve, então, abandonar suas pretensões metafísicas e dedicar-se a ser uma espécie de organon das ciências particulares.

Por fim, a antologia reúne, ainda, textos que tratam da arte, considerada como uma forma de expressão privilegiada da vida. Como se vê, o enfoque reproduz aquela tríade já indicada: vida, expressão, compreensão. O que diferencia a arte é que ela é uma objetivação mais imediata do que o conhecimento por meios abstratos, como ocorre nas ciências. Os verdadeiros poetas - e para Dilthey o modelo é Goethe, como no seu célebre estudo "Goethe e a fantasia poética", coligido na antologia - são capazes de exprimir vivências no limite supraindividuais ou, formulando de outro modo, eles dão vazão àquela dimensão humana genérica (Allgemein-Menschlich) que está na base de nossa existência (Dilthey, 2010a: 323, 441, 443, 446). Isto tem sua razão de ser: ao contrário do homem comum, o poeta, mesmo sem o saber, concretiza uma relação de vida e expressão diferente. Nele, o que é vivenciado é transformado inteiramente em expressão, pois há um "nexo estrutural entre o vivenciado e a expressão do vivenciado" (Dilthey, 2010a: 344). O resultado, claro está, é uma intensificação extraordinária, potente e única da tríade. É isso que torna, para Dilthey, a arte tão importante. Ademais, há um outro desdobramento significativo, a questão da época como unidade, já mencionada. O artista, por estar imerso em um contexto social-histórico, é determinado pela época, mas ao mesmo tempo a transcende, como manifestação do humano genérico - em uma síntese que, por fim, exprime tanto aquela como este, e coloca a obra de arte em uma posição absolutamente única com relação ao nexo vida-expressão-compreensão. Ou seja: com o núcleo vivo do mundo dos seres humanos, histórico e social.

Resenha recebida para publicação em junho de 2011.

Leopoldo Waizbort é professor da Universidade de São Paulo (USP) e pesquisador do Conselho Nacional de Desenvolvimento Científico e Tecnológico (CNPq). Autor de As aventuras de Georg Simmel (2000) e A passagem do três ao um: crítica literária, sociologia, filologia (2007). 


\section{NOTAS}

1 Até onde vai meu conhecimento, são esses os títulos já traduzidos para o português: Leibniz e a sua época (1947); Teoria das concepções de mundo (1992); Sistema da ética (1994); História da filosofia (s.d. e 1994); Ideias para uma psicologia descritiva e analítica (2002).

2 o que propicia assinalar o duvidoso da solução proposta pela edição da Unesp, que desde o título traduz Geisteswissenschaften como "ciências humanas". Embora ao primeiro olhar possa parecer uma solução aceitável, ela ignora, e anula, a carga semântica, altamente relevante, de Geist.

3 No entender de Vico, é possível o acesso e a compreensão de todas as formas do espírito humano, mesmo as mais distantes e estranhas em tempo e espaço, pois todas elas são figurações de nosso próprio espírito humano, "modificazioni della nostra medesima mente umana", como diz ele. Assim, mediante uma espécie de evocação (ou re-evocação) da consciência individual é possível o acesso a toda a história (Vico, 1999: 131).

4 Sobre o assunto, ver König \& Lämmert (1993). Para o contexto brasileiro, vale lembrar a inspiração diltheyana decisiva da Geistesgeschichte elaborada por Otto Maria Carpeaux.

5 Já nos anos 1960, esse era o juízo de Péter Szondi (1975).

6 Desenvolvimento decisivo será encontrado na grande obra de Ernst Troeltsch, Der Historismus und seine Probleme (1922), aliás dedicada à memória de Dilthey.

7 O leitor sociólogo logo atenta para o nexo, fundante na sociologia weberiana, de análise de processo histórico-desenvolvimental e perspectiva comparatista.

8 A questão é formulada, em outros termos, por Gadamer (1965: 223).

9 Inicialmente, por Georg Simmel, em sua Über sociale Differenzierung, de 1890, e, a partir de então, em variados escritos seus e de outros.

10 Wechselwirkung é um termo de difícil versão, sendo recorrentemente traduzido por "interação", "ação recíproca" ou mesmo "interação circular". Ele é desenvolvido com o intuito de se contrapor à ideia de causalidade, relevante na arqui- 
tetônica kantinana e na filosofia crítica dela derivada. Entretanto, já em 1799 Schleiermacher havia posto o conceito de Wechselwirkung em nexo similar de sentido; como Dilthey foi um dos responsáveis pela "redescoberta" e revalorização do pensamento desse filósofo, é possível que tenha nele se inspirado para procurar desenvolver seu argumento para além do causalismo. O desenvolvimento posterior ficará a cargo de Georg Simmel, que eleva a Wechselwirkung à pedra de toque de seu pensamento.

11 Habermas destaca bem essa dimensão, que abre as portas para uma virada linguística como a sua (1987: 170).

12 "A compreensão brota inicialmente nos interesses da vida prática. Nesta, as pessoas estão referidas umas às outras por meio da comunicação. Elas precisam se fazer mutuamente compreensíveis. Uma precisa saber o que a outra quer. Assim originam-se inicialmente as formas elementares da compreensão. Elas são como letras, cujo encadeamento torna possível formas mais elevadas de compreensão." (Dilthey, 2010a: 253, tradução alterada).

13 Ver, também, "O espírito só compreende aquilo que ele mesmo criou" (Dilthey, 2010a: 201, tradução alterada); e Dilthey (1970: 347, 179-180).

14 Um ótimo exemplo é Spitzer (1955: 39-41).

15 Opinião diversa sustenta Riedel (1970: 15, 46-47).

16 Adorno, em suas "Lições de filosofia da história", desenvolveu crítica similar; veja-se Adorno (2006: 400).

17 Ver Koselleck (1989), assim como os volumes posteriores de ensaios do mesmo autor.

\section{REFERÊNCIAS BIBLIOGRÁFICAS}

Adorno, Theodor. Zur Lehre von der Geschichte und von der Freiheit. Frankfurt am Main: Suhrkamp, 2006.

Dilthey, Wilhelm. Leibniz e a sua época. São Paulo: Saraiva, 1947.

. Der Aufbau der geschichtlichen Welt in den Geisteswissenschaften. Frankfurt am Main: Suhrkamp, 1970.

. Teoria das concepções de mundo. Lisboa: 70, 1992. 
Sistema da ética. São Paulo: Ícone, 1994

. História da filosofia. Lisboa: Presença, s.d.; São Paulo: Hemus, 1994.

Ideias para uma psicologia descritiva e analítica. Lisboa: 70, 2002.

. Filosofia e educação: textos selecionados. São Paulo: Edusp, 2010a.

. A construção do mundo histórico nas ciências humanas. São Paulo: Ed. Unesp, 2010b.

Gadamer, Hans-Georg. Wahrheit und Methode. 2. ed. Tübingen: J. C. B. Mohr, 1965.

Habermas, Jürgen. Conhecimento e interesse. Rio de Janeiro: Guanabara, 1987.

König, Christoph \& Lämmert, Eberhard (orgs.). Literaturwissenschaft und Geistesgeschichte 1920 bis 1925. Frankfurt am Main: Fischer, 1993.

Köhnke, Klaus Christian. Entstehung und Aufstieg der Neukantianismus. Frankfurt am Main: Suhrkamp, 1986.

Koselleck, Reinhart. Vergangene Zukunft. Frankfurt am Main: Suhrkamp, 1989.

Löwith, Karl. Von Hegel zu Nietszche. Hamburg: Meiner, 1995.

Riedel, Manfred. Einleitung. In: Dilthey, W. Der Aufbau der geschichtlichen Welt in den Geisteswissenschaften. Frankfurt am Main: Suhrkamp, 1970.

Simmel, Georg. Uber sociale Differenzierung. Leipzig: Duncker \& Humblot, 1890.

Spitzer, Leo. Linguistica e historia literaria. Madri: Gredos, 1955. Szondi, Péter. Einführung in die literarische Hermeneutik. Frankfurt am Main: Suhrkamp, 1975.

Troeltsch, Ernst. Der Historismus und seine Probleme. Tübingen: J. C. B. Mohr (Paul Siebeck), 1922,

Vico, Giambattista. A ciência nova. Rio de Janeiro: Record, 1999. 